\title{
Intra- and postoperative complications in 137 cases of giant thyroid gland tumor
}

\author{
WEI DU ${ }^{1 *}$, SHAN-TING LIU $^{1 *}$, PENG LI $^{1 *}$, LI-YAN SUN ${ }^{2}$, MING ZHAO $^{1}$, JIN-XING QI $^{1}$, \\ RUI-HUA LUO ${ }^{1}$, LU FENG ${ }^{1}$, LI-YUAN DAI ${ }^{1}$, MENG CUI ${ }^{1}$, CHANG-FU SUN ${ }^{3,4}$ and FA-YU LIU ${ }^{3,4}$ \\ ${ }^{1}$ Department of Head and Neck Surgery, Henan Tumor Hospital, Zhengzhou University; \\ ${ }^{2}$ Department of Orthodontics, Henan Sais Stomatological Hospital, Zhengzhou, Henan 450008; \\ Departments of ${ }^{3}$ Oromaxillofacial-Head and Neck Surgery and ${ }^{4}$ Oral and Maxillofacial Surgery, \\ School of Stomatology, China Medical University, Heping, Shenyang, Liaoning 110002, P.R. China
}

Received March 29, 2012; Accepted July 12, 2012

DOI: $10.3892 / \mathrm{ol} .2012 .847$

\begin{abstract}
The intra- and postoperative complications resulting from surgery for giant thyroid gland tumors (diameter greater than $10 \mathrm{~cm}$ ) present serious challenges to patient recovery. Although there are a number of methods, all have limitations. In this study, we present our experience with several complications of surgical treatment of giant thyroid gland tumors to increase the awareness and aid the prevention of these complications. A total of 137 consecutive patients who underwent surgical treatment in Henan Tumor Hospital were retrospectively analyzed. Statistics pertaining to the patients' clinical factors were gathered. We found that the most common surgical complications were recurrent laryngeal nerve (RLN) injury and symptomatic hypoparathyroidism. Other complications included incision site infections, bleeding, infection and chyle fistula, the incidence of which increased significantly with increasing extent of surgery from group I (near-total thyroidectomy) to group V (total thyroidectomy plus lateral neck dissection). Low complication rates may be achieved with more accurate knowledge of the surgical anatomy, skilled surgical treatment and experience. More extensive surgery results in a greater number of complications.
\end{abstract}

\section{Introduction}

Thyroid surgery, in particular to treat giant thyroid gland tumor, is a potentially dangerous operation due to the long course of disease and the surrounding anatomical changes, meaning that the incidence of intra- and postoperative complications is

Correspondence to: Dr Peng Li, Department of Head and Neck Surgery, Henan Tumor Hospital, Zhengzhou University, 127 Dongming Road, Zhengzhou, Henan 450008, P.R. China E-mail: lipeng1528@163.com

*Contributed equally

Key words: complications, giant thyroid gland, recurrent laryngeal nerve, hypoparathyroidism likely to be higher than in cases with normal thyroid nodules. Thyroidectomy is one of the most frequent surgeries performed in patients with giant thyroid gland tumors, especially those with thyroid cancer (1). Improvements in anesthesia and antisepsis, as well as better surgical instrumentation and improvements in surgical technique, have rendered thyroidectomy an efficacious and safe treatment modality with acceptable morbidity and even unrecorded mortality. However, the optimal extent of thyroid resection and lymph node dissection remain controversial. Central compartment node dissection (CCND) is usually performed with near-total thyroidectomy (NTT) for prophylactic purposes. while lateral neck dissection (LND) is performed only when thyroid carcinoma is pathologically confirmed according to the National Comprehensive Cancer Network (NCCN) Clinical Practice Guidelines in Oncology. (http://www.nccn.org/professionals/physician_gls/f_ guidelines.asp\#thyroid)

A giant thyroid gland tumor (Figs. 1 and 2) is defined as any thyroid with an average weight greater than $500 \mathrm{~g}$, a diameter greater than $10 \mathrm{~cm}$, extending up to the mandibular angle, a lower level extended to the sternum and in which both sides of the posterior border are normally sternocleidomastoid muscle. The main concern is the potentially high rate of complications, including hematoma, permanent recurrent laryngeal nerve (RLN) paralysis and hypoparathyroidism $(2,3)$. In this study, we present our experience with several complications of surgical treatment of giant thyroid gland tumors to increase the awareness and aid the prevention of these complications.

\section{Patients and methods}

Patients. A total of 137 patients who underwent giant thyroid gland tumor surgery at the Thyroid Disease Diagnosis and Treatment Center (Department of Head and Neck, Henan Tumor Hospital, Zhengzhou University, Henan, China) between January 2001 and December 2010 approved a retrospective review of the images and medical records.

According to the retrospective review of the images and medical records of patients over 10 years, all patients underwent routine measurements of serum calcium, phosphorus, WBC, and parathyroid hormone levels pre-postoperative and 
examination of vocal cord movement by direct laryngoscopy Complication rates were assessed according to the extent of surgery, which was classified as follows: NTT (group I, $\mathrm{n}=71$ ); total thyroidectomy (TT; group II, $\mathrm{n}=24$ ); NTT-CCND (group III, $\mathrm{n}=11$ ); TT-CCND (group IV, $\mathrm{n}=19$ ); TT-LND (group $\mathrm{V}, \mathrm{n}=12$ ).

Patients' charts were reviewed for patient demographics and clinicopathological characteristics, inlcuding age, gender, history, the length of hospitalization, tumor size, comorbid disease (including hypertension, cardiac disease and diabetes mellitus) and pathological diagnosis. Complication rates according to the extent of thyroid surgery included RLN injury (permanent or transient), symptomatic hypoparathyroidism (permanent or transient), incision site infections, bleeding, chyle fistula and Horner's syndrome. All patients with intra- or postoperative complications attended our endocrine outpatient clinic at regular intervals until 5 years after the surgery. During follow-up visits, a complete patient evaluation was performed, including medication, physical examination and blood sampling for serum calcium levels. Patients who developed a postoperative complication and were unable to attend the outpatient clinic were consulted by telephone. Local Ethical Committee approval was granted for the use of surgical trimming and informed consent was also obtained from the patients prior to surgery.

Statistical analysis. The intra- and postoperative complications and their rates were assessed for each of the five patient groups and comparisons among groups were made using Fisher's exact test; when necessary, data were transformed to obtain results distributed with equal variance. Pearson's Chi-square test was used to assess the correlations among the groups. $\mathrm{P}<0.05$ was considered to indicate a statistically significant result. All analyses were performed using statistical package for social science (SPSS), version 13.0 (SPSS Inc., Chicago, IL, USA).

\section{Results}

Patient characteristics. From a review of medical records, 137 thyroidectomies were identified. Of the patients, $121(88 \%)$ were operated on for the first time and there were $16(12 \%)$ reoperations. There were 26 males and 111 females, with a mean age of 47.8 years (Table I). The mean history period was 4.9 years and the mean duration of hospitalization was 8.2 days. The 137 cases evaluated were split into two groups according to pathological diagnosis: i) 98 (72\%) patients who had benign pathology, including 71 thyroid adenoma (52\%) patients and 27 (20\%) patients with nodular goiters (Fig. 2); and ii) 39 (28\%) patients with a malignant pathology (Fig. 1). The latter malignant pathologies were differentiated in $36(26.3 \%)$ cases, medullary in $2(1.5 \%)$ and undifferentiated in $1(0.7 \%), 39$ totally $(28.5 \%)$. Patients' data on the indications for surgery, operative time, length of hospital stay, age and gender are listed in Table I.

Complications. In the present study, permanent RLN injury was found in $2.9 \%$ of cases (Table II). A total of 54\% of surgeons individuated the RLN, $42 \%$ uncovered it anatomically and $4 \%$ did not search for it. However, the temporary RLN injury incidence rates increased with increasing extent of surgery, with incidences of $1.4,8.4,9.1,10.5$ and $16.7 \%$ in groups I, II, III, IV and V, respectively (Table II). All the surgeons noted care was taken not to injure the external branch of the laryngeal superior nerve (LSN). LSN injury was diagnosed by an otolaryngologist following indirect laryngoscopy or videolaryngostroboscopy of the patients with difficulty in producing a high-pitched voice.

Symptomatic hypocalcemia, which was observed in 27 (19.7\%) patients (16.8\% transient), accounted for $37.5 \%$ of all complications. The incidence of transient hypoparathyroidism was 5.6, 20.8, 27.3, 31.6 and $41.7 \%$ in groups I, II, III, IV and $\mathrm{V}$, respectively. Definitive permanent hypocalcemia following surgical interventions for thyroid cancer was higher, particularly with the extent of surgery.

Transient or permanent LSN injury was observed in 10 patients (7.3\%; statistically significant). Hemorrhage accounted for $2.9 \%(4 / 137)$ of the total complications and was not statistically significant in groups I-V or associated with the extent of surgery.

\section{Discussion}

Due to new monitoring technology, the incidence rate of thyroid gland tumor has been increasing over recent years (4) with no change in mortality rates. Of these tumors, $50 \%$ have a diameter less than $2 \mathrm{~cm}$ and the incidence rate of giant thyroid gland tumors, especially those with a diameter greater than $10 \mathrm{~cm}$, is lower.

Thyroid surgery takes place in an area of complicated anatomy in which a number of vital physiological functions and senses are controlled. Improved knowledge of the surgical anatomy of the neck, thyroid pathology and required surgical treatment is essential to keep complications within reasonable limits (5). Complications are often dependent on physical factors, including a large or intrathoracic goiter, extensive malignancy and whether the surgery is a primary or secondary procedure (6). The three main complications following thyroid surgery are RLN palsy, hypoparathyroidism and postoperative hemorrhage (7). In the present study, we found that intra- and postoperative complications following thyroid surgery may include transient or permanent hypoparathyroidism, transient or permanent EB-SLN lesions, transient or permanent RLN lesions, wound infection, hematoma, chyle fistula, Horner's syndrome and injury to motor nerves in the neck.

Hyperparathyroidism is a major concern leading to prolonged hospitalization and increased cost. In several studies $(1,6,8)$, the incidence of transient hypocalcemia varied from 6.9 to $46 \%$, while a rate of 0.4 to $33 \%$ has been reported for permanent hypoparathyroidism. In the present study, transient hypoparathyroidism occurred in $16.8 \%$ of cases. Patients with permanent hypoparathyroidism require life-long treatment with calcium and vitamin $\mathrm{D}$, so this complication is considered serious. Certain authors $(2,9)$ believe that a single functioning gland is sufficient to restore normal parathyroid activity, whereas others suggest that the integrity of at least three glands is necessary (10). Transient hypoparathyroidism, however, rarely affects quality of life. In our series, the incidence rates of transient and permanent hypoparathyroidism increased significantly with increasing extent of surgery. Therefore it is necessary to take certain technical precautions to reduce as much as possible the incidence of persistent hypocalcemic complications. 

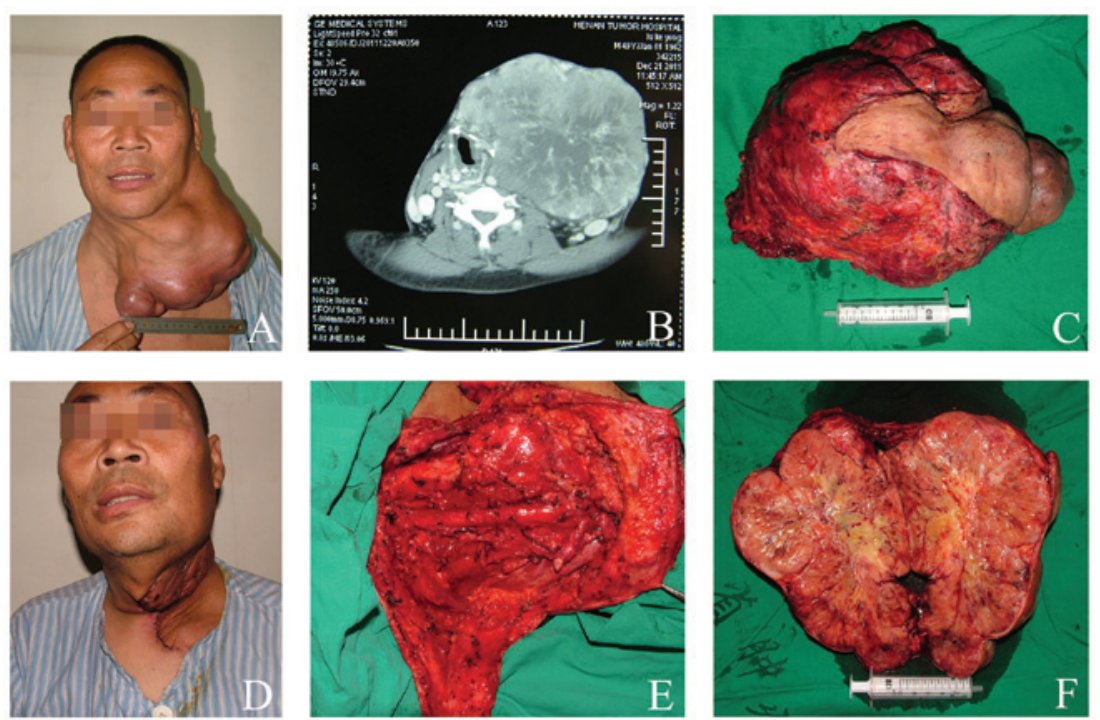

Figure 1. Giant thyroid papillary carcinoma (Name, Lu XX; history, 11 years; diameter of tumor, $21 \mathrm{~cm}$; weight of tumor, 4,200 g; hospital stay, 12 days; surgery time, $185 \mathrm{~min}$ ). (A) Preoperative giant thyroid papillary carcinoma, causing dyspnea and limitation of movement. (B) Preoperative computerized tomography scan showing oppressed trachea. (C and F) Specimen of giant thyroid papillary carcinoma was solid. (D) Stitches after 8 days showing flap edema with no significant contour deformity. (E) Neck dissection was completed with internal jugular vein ligation.
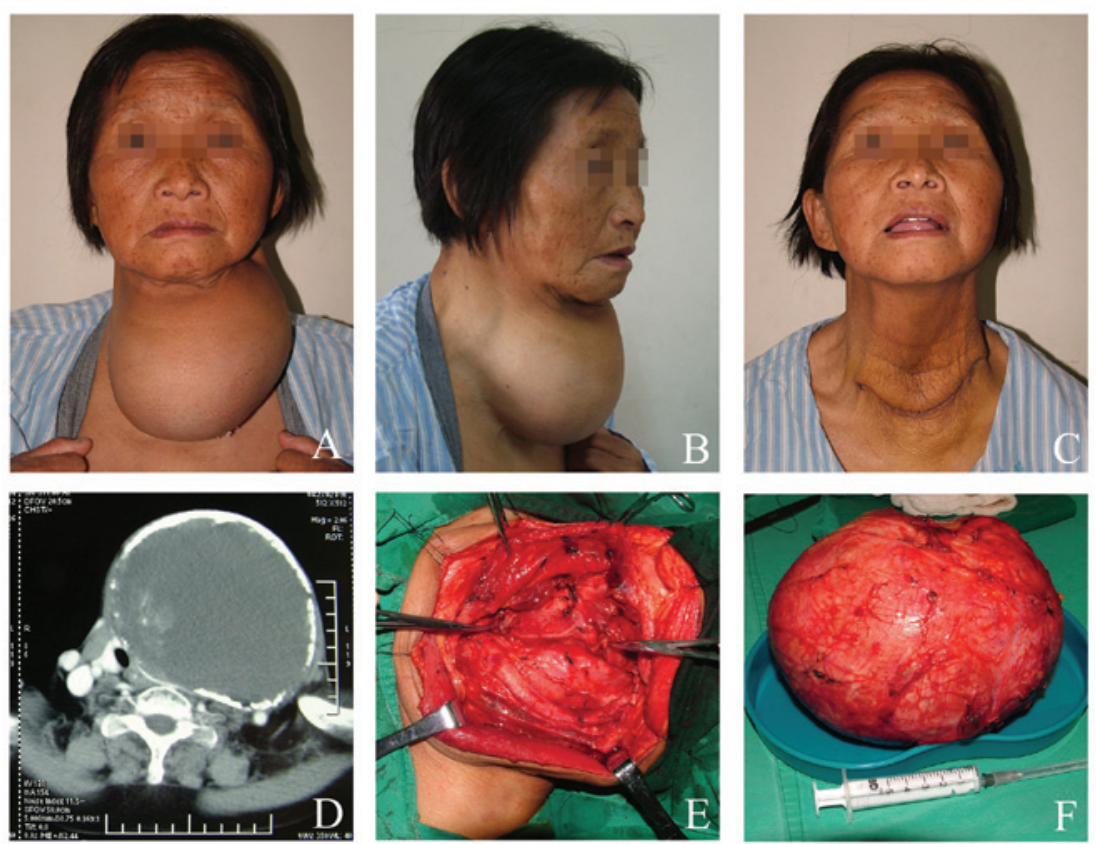

Figure 2. Giant thyroid nodular goiter (Name, Cao XX; history, 8 years; diameter of tumor, $16 \mathrm{~cm}$; weight of tumor, 2,800 g; hospital stay, 8 days; surgery time, $108 \mathrm{~min}$ ). (A and B) Preoperative giant thyroid nodular goiter, causing dyspnea and limitation of movement and sleeping. (C) Stitches after 8 days. The flap was folded and drooping. (D) Preoperative computerized tomography scan showing calcified capsule wall and oppressed trachea. (E and F) Specimen of giant thyroid nodular goiter showing circumference and boundary cleared.

Transient or definitive injuries to the RLN are the most serious complications as they influence the patient's quality of life, similar to permanent hypoparathyroidism. The incidence of permanent RLN injury has been reported to range between 0 and $4 \%(11,12)$, similar to that found in the present study. The permanent RLN lesions occurred less often in group I. However, there was a mild increase in transient monoplegia and a similar incidence of diplegia in this group. Although prevention of injury can never be absolute, careful observation during every operative step to monitor the wide range of possible varia- tions in the course of the nerve should substantially reduce the risk (13). Certain studies compared the complication rates associated with total and subtotal thyroidectomy in benign nodular disease and did not identify any significant difference between the two procedures $(2,6,13)$. In the present study, the preferred surgical technique did not influence postoperative complication rates. Dralle et al (14) concluded that routine visual nerve identification and preservation should be the gold standard in thyroid surgery. In our institution, intra-operative nerve identification is the standard practice and thus was not analyzed 
Table I. Demographic and clinicopathological characteristics of patients.

\begin{tabular}{|c|c|c|c|c|c|c|}
\hline Parameters & $\begin{array}{c}\text { Total } \\
(n=137)\end{array}$ & $\begin{array}{c}\text { Group I } \\
(n=71)\end{array}$ & $\begin{array}{c}\text { Group II } \\
(\mathrm{n}=24)\end{array}$ & $\begin{array}{c}\text { Group III } \\
(\mathrm{n}=11)\end{array}$ & $\begin{array}{c}\text { Group IV } \\
(\mathrm{n}=19)\end{array}$ & $\begin{array}{c}\text { Group V } \\
(n=12)\end{array}$ \\
\hline Age (mean, years) & 47.8 & 48.6 & 47.4 & 46.9 & 45.5 & 49.3 \\
\hline Gender (male:female) & $26: 111$ & $12: 59$ & $4: 20$ & $3: 8$ & $4: 15$ & $3: 9$ \\
\hline History (mean, years) & 4.9 & 5.1 & 4.6 & 3.9 & 4.3 & 6.7 \\
\hline Tumor size (mean, cm) & 13.1 & 11.6 & 15.1 & 13.0 & 14.3 & 16.2 \\
\hline \multicolumn{7}{|l|}{ Comorbid diease } \\
\hline Hypertension (n) & 19 & 10 & 3 & 2 & 3 & 1 \\
\hline Diabetes mellitus (n) & 12 & 6 & 2 & - & 2 & 2 \\
\hline Cardiac disease (n) & 13 & 5 & 4 & 1 & 1 & 2 \\
\hline Capsular invasion (\%) & 54.5 & 31.4 & 55.8 & 72.6 & 73.2 & 78.9 \\
\hline \multicolumn{7}{|l|}{ Pathological diagnosis } \\
\hline Thyroid adenoma & 71 & 54 & 17 & - & - & - \\
\hline Nodular goiter & 27 & 15 & 12 & - & - & - \\
\hline Thyroid carcinoma & 39 & - & 7 & 9 & 21 & 2 \\
\hline Hospital stay (mean, days) & 8.2 & 6.9 & 8.2 & 9.3 & 10.5 & $11.2^{\mathrm{a}}$ \\
\hline Surgery time (mean, minutes) & 126.3 & 107.2 & 115.1 & 140.7 & 155.9 & 201.6 \\
\hline
\end{tabular}

Table II. Intra- and postoperative rates according to the extent of thyroid surgery.

\begin{tabular}{|c|c|c|c|c|c|c|}
\hline \multirow[b]{2}{*}{ Parameters } & \multicolumn{6}{|c|}{ Percentage of cases (n) } \\
\hline & $\begin{array}{c}\text { Total } \\
(\mathrm{n}=137)\end{array}$ & $\begin{array}{l}\text { Group I } \\
(\mathrm{n}=71)\end{array}$ & $\begin{array}{c}\text { Group II } \\
(\mathrm{n}=24)\end{array}$ & $\begin{array}{l}\text { Group III } \\
(\mathrm{n}=11)\end{array}$ & $\begin{array}{c}\text { Group IV } \\
(\mathrm{n}=19)\end{array}$ & $\begin{array}{c}\text { Group V } \\
(\mathrm{n}=12)\end{array}$ \\
\hline \multicolumn{7}{|l|}{ Hypoparathyroidism } \\
\hline Transient & $16.8(23)$ & $5.6(4)$ & $20.8(5)$ & $27.3(3)$ & $31.6(6)$ & $41.7(5)$ \\
\hline Permanent & $2.9(4)$ & $1.4(1)$ & - & $9.1(1)$ & $5.3(1)$ & $8.3(1)$ \\
\hline \multicolumn{7}{|l|}{ EB-LSN lesions } \\
\hline Transient & $5.1(7)$ & $2.8(2)$ & $4.2(1)$ & $9.1(1)$ & $10.5(2)$ & $8.3(1)$ \\
\hline Permanent & $2.1(3)$ & - & $4.2(1)$ & - & $5.3(1)$ & $8.3(1)$ \\
\hline \multicolumn{7}{|l|}{ RLN lesions } \\
\hline Transient & $5.8(8)$ & $1.4(1)$ & $8.4(2)$ & $9.1(1)$ & $10.5(2)$ & $16.7(2)$ \\
\hline Permanent & $2.9(4)$ & - & $4.2(1)$ & $9.1(1)$ & $5.3(1)$ & $8.3(1)$ \\
\hline Wound infection & $3.6(5)$ & $1.4(1)$ & $4.2(1)$ & $9.1(1)$ & $5.3(1)$ & $8.3(1)$ \\
\hline Flap edema & $5.1(6)$ & $1.4(1)$ & - & $9.1(1)$ & $10.5(2)$ & $16.7(2)$ \\
\hline Hematoma & $2.9(4)$ & $1.4(1)$ & $4.2(1)$ & - & $5.3(1)$ & $8.3(1)$ \\
\hline Chyle fistula & $2.9(4)$ & $1.4(1)$ & - & $9.1(1)$ & $5.3(1)$ & $8.3(1)$ \\
\hline Horner's syndrome & $2.2(3)$ & - & - & $9.1(1)$ & $5.3(1)$ & $8.3(1)$ \\
\hline
\end{tabular}

as an independent risk factor. In fact, certain surgeons believe that it is important to save some thyroid tissue around the nerve junction to the larynx, and some skilled, experienced surgeons have obtained a low nerve injury rate without deliberate routine nerve exposure. When cord paralysis with dysphonia occurs days or weeks following surgery, the surgeon should consider 
that the symptom is associated with RLN injury. It is important to start logopedic rehabilitation early (within 2-3 weeks) in all cases of vocal cord paralysis. Patients with vocal cord palsy should start logopedic rehabilitation as early as possible.

Although innervating only one muscle, the cricothyroideus, the LSN is important in providing a normal voice. The role of this nerve and its muscle is to tense the vocal cords, providing timbre to the voice. LSN transient or permanent injuries are relatively frequent and are often underestimated. Although certain surgeons insist on direct visualization of the external branch of the superior laryngeal nerves in all cases, most surgeons do not, considering it unnecessary in most cases as the nerve is not thought to be at risk $(2,3,12)$. It is rarely possible to individuate the external branch of the LSN easily and immediately as it is extremely thin or incorporated in the lower pharyngeal constrictor muscle sheath. An obstinate anatomical search may cause nerve damage. It should be noted that approximately $20 \%$ of patients are at risk of injury to the external branch of the LSN when the superior thyroid vessels are clamped, divided and ligated en masse, a technique that was commonly used prior to the anatomy of the external branch with its variations being well described.

Hematoma following thyroidectomy is a life-threating early complication of thyroid surgery in various series and its incidence rate is reported to be $0.3-1.5 \%$ (15). In the present study, hematoma was a complication in $2.9 \%$ of cases and reoperation was undertaken in 9 due to ongoing hemorrhage and airway obstruction. None required reopening of the wound.

Chyle fistula and Horner's syndrome are rare and troublesome complications. Chyle fistula is usually identified upon postoperative commencement of an oral diet and is indicated by milky drainage, a sudden increase in drainage volume, bulging supraclavicular fossa and induration or erythema of the skin $(1,3,16,17)$. Horner's syndrome is usually associated with unique clinical features based on the anatomical location of the underlying pathological process. Careful dissection around the prevertebral fascia and the carotid sheath is necessary to avoid injury to the sympathetic chains when performing a radical neck dissection.

Flap edema (Figs. 1 and 2) rates were higher in patients who had a large gland size and were operated on by the resident surgeon. The incidence of flap edema varied in total from 0.3 to $7 \%(1,15)$. Flap edema may be due to inadequate surgical technique with damage of the lymphatic vessels and results in poor venous circulation due to hemostasis over the ligation.

At the beginning of the 20th century, postoperative infection was a major complication of thyroidectomy. At present, with the benefit of antisepsis and the constant progress of surgical techniques, the overall risk of postoperative wound infection is substantially decreased. In our series, infection occurred in 5 cases $(3.6 \%)$, all of which were successfully managed with wound debridement and antibiotics. We did not identify any association between wound infection and extent of thyroid resection. No differences were noted among patients administered an antibiotic as prophylaxis, therapy or not at all.

In conclusion, these complications of thyroidectomy may cause significant difficulty for patients and a significant sense of discomfort for the surgeon. The results of our study suggest that most giant thyroid gland tumor surgeries are safe and may be performed with minimal morbidity, but an increased risk of surgical complications, particularly hypoparathyroidism, remains a problem that needs be solved in patients who require more extensive surgery. Low complications rates may be achieved with more detailed knowledge of the surgical anatomy, skilled surgical treatment and experience. It is clear that to achieve low complication rates, surgeons should be appropriately trained, follow best practice and maintain their level of commitment and good communication until the outcome is ensured.

\section{Acknowledgements}

We gratefully acknowledge members of the Department of Medical Records Room and Data Center, Henan Tumor Hospital, Zhengzhou University, for their excellent technical assistance.

\section{References}

1. Moulton-Barrett R, Crumley R, Jalilie S, Segina D, Allison G, Marshak D and Chan E: Complications of thyroid surgery. Int Surg 82: 63-66, 1997.

2. Dener C: Complications rates after operations for benign thyroid disease. Acta Otolaryngol 122: 679-683, 2002.

3. Olson SE, Starling J and Chen H: Symptomatic benign multinodular goiter: unilateral or bilateral thyroidectomy? Surgery 142: 458-462, 2007.

4. Rego-Iraeta A, Pérez-Méndez LF, Mantinan B and GarciaMayor RV: Time trends for thyroid cancer in northwestern Spain: true rise in the incidence of micro and larger forms of papillary thyroid carcinoma. Thyroid 19: 333-340, 2009.

5. Bliss RD, Gauger PG and Delbridge LW: Surgeon's approach to the thyroid gland: surgical anatomy and the importance of technique. World J Surg 24: 891-897, 2000.

6. al-Suliman NN, Ryttov NF, Qvist N, Blichert-Toft M and Graversen HP: Experience in a specialist thyroid surgery unit: a demographic study, surgical complications, and outcome. Eur J Surg 163: 13-20, 1997

7. Ozbas S, Kocak S, Aydintug S, Cakmak A, Demirkiran MA and Wishart GC: Comparison of the complications of subtotal, near total and total thyroidectomy in the surgical management of multinodular goitre. Endocr J 52: 199-205, 2005.

8. Percival RC, Hargreaves AW and Kanis JA: The mechanism of hypocalcemia following thyroidectomy. Acta Endocrinol (Copenh) 109: 220-226, 1985.

9. Sasson AR, Pingpank JF Jr, Wetherington RW, Hanlon AL and Ridge JA: Incidental parathyroidectomy during thyroid surgery does not cause transient symptomatic hypocalcaemia. Arch Otolaryngol Head Neck Surg 127: 304-308, 2001.

10. Pattou F, Combemale F, Fabre S, Carnaille B, Decoulx M, Wemeau JL, Racadot A and Proye C: Hypocalcemia following thyroid surgery: incidence and prediction of outcome. World $\mathbf{J}$ Surg 22: 718-724, 1998.

11. Iyer NG and Shaha AR: Management of thyroid nodules and surgery for differentiated thyroid cancer. Clin Oncol 22: 405-412, 2010.

12. Abadin SS, Kaplan EL and Angelos P: Malpractice litigation after thyroid surgery: the role of recurrent laryngeal nerve injuries, 1989-2009. Surgery 148: 718-722, 2010.

13. Hunt PS, Poole M and Reeve TS: A reappraisal of the surgical anatomy of the thyroid and parathyroid glands. Br J Surg 55: 63-66, 1968.

14. Dralle H, Sekulla C, Haerting J, Timmermann W, Neumann HJ, Kruse E, Grond S, Mühlig HP, Richter C, Voss J, et al: Risk factors of paralysis and functional outcome after recurrent laryngeal nerve monitoring in thyroid surgery. Surgery 136: 1310-1322, 2004.

15. Taneri F, Kurukahvecioglu O, Ege B, Yilmaz U, Tekin E, Cifter C and Onuk E: Prospective analysis of 518 cases with thyroidectomy in Turkey. Endocr Regul 39: 85-90, 2005.

16. Gregor RT: Management of chyle fistulization in association with neck dissection. Otolaryngol Head Neck Surg 122: 434-439, 2000.

17. Rodgers GK, Johnson JT, Petruzzelli GJ, Warty VS and Wagner RL: Lipid and volume analysis of neck drainage in patients undergoing neck dissection. Am J Otolaryngol 13: 306-309, 1992. 